\title{
The pivotal role of the angiotensin-II-NF-KB axis in the development of COVID-19 pathophysiology
}

\author{
Hiroshi Okamoto $^{1} \cdot$ Naomi Ichikawa $^{1}$
}

Received: 11 September 2020 / Revised: 14 September 2020 / Accepted: 16 September 2020 / Published online: 2 November 2020

(c) The Japanese Society of Hypertension 2020

Coronavirus disease 2019 (COVID-19) is caused by the virus severe acute respiratory syndrome coronavirus 2 (SARS-CoV-2). SARS-CoV-2 can infect host cells by interacting with membrane-bound angiotensin-converting enzyme 2 (ACE2) on the respiratory epithelium. ACE2 is part of the renin-angiotensin system (RAS), and treatment with RAS inhibitors can increase the tissue expression of ACE2 and its presentation at the cell surface. Thus, it has been suggested that treatment with ACE inhibitors or angiotensin receptor blockers might increase the risk of COVID-19 after exposure to SARS-CoV-2. However, there are several reports showing that the treatment of hypertension with RAS inhibitors is not associated with a substantial increase in the likelihood of a positive test for COVID-19 or in the risk of severe COVID-19 [1, 2]. Recently, Matsuzawa et al. suggested that RAS inhibitors do not increase the risk of COVID19. Furthermore, they propose that RAS inhibitors reduce the risk of disease severity among older age individuals and patients with diabetes. RAS inhibitors have been reported to play a role in the reduction of inflammation by blocking the downregulation of ACE2 and the hyperactivation of RAS [3]. It is also suggested that elevated angiotensin II plays a crucial pathological role in the development of severe COVID-19 [4]. As shown in Fig. 1, angiotensin II has been shown to activate nuclear factor kappa-B (NF- $\mathrm{KB}$ ) through binding to angiotensin-II type 1 receptor (AT1 receptor). Once angiotensin II binds to AT1, CARD and membrane-associated guanylate kinase-like protein, B-cell lymphoma 10, and mucosaassociated lymphoid tissue lymphoma translocation protein 1 compose the CBM signalosome and activate

Hiroshi Okamoto

h-okamoto0502@dream.bbexcite.jp

1 Minami-Otsuka Institute of Technology, Minami-Otsuka Clinic, Tokyo, Japan the IкB kinase complex, which is composed of three subunits $(\alpha, \beta$, and $\gamma)$, resulting in the phosphorylation of I $\mathrm{B}$ (inhibitor of NF- $\kappa \mathrm{B}$ ). The most prevalent activated forms of NF- $\mathrm{KB}$ is the heterodimer of p65 and p50. Without activation of the cell, I $\mathrm{KB}$ in the cytoplasm binds to the p65 and p50 subunits of NF- $\mathrm{kB}$ to prevent the nuclear translocation of NF- $\kappa \mathrm{B}$. On the other hand, with activation of cells, such as by angiotensin II-AT1 binding, IкB is phosphorylated at Ser 32/36 occurs, which promotes the degradation of IкB to release the $\mathrm{p} 65$ and p50 subunit of NF- $\mathrm{BB}$, resulting in the nuclear translocation of NF- $\mathrm{KB}$. After nuclear translocation, NF$\kappa \mathrm{B}$ binds to its specific binding site on DNA to activate gene expression in association with transcription machinery, such as coactivators. NF- $\mathrm{KB}$ is a transcription factor that regulates the gene expression of inflammatory cytokines such as interleukin-6, monocyte chemoattractant protein 1, AT1 receptor, and platelet-derived growth factor-beta (PDGF-B) in several cells [5, 6]. Therefore, in concert with the immunological attack on the virus, the elevation of angiotensin II by SARS-CoV2 infection could induce NF- $\mathrm{KB}$ activation in bronchial epithelial cells and vascular endothelial cells, leading to the recruitment of inflammatory cells and enhanced cytokine/chemokine and PDGF-B expression. This series of events results in the cytokine storm and massive inflammation of the lung and systemic vascular systems commonly observed upon SARS-CoV2 infection. In particular, patients with diabetes have been reported to maintain a state of inflammation through chronic activation of the NF- $\kappa B$ pathway [7]. It has also been reported that the constitutive activation of NF- $\kappa B$ is a ubiquitous phenomenon among various cell types in the aging phenotype; therefore, aged individuals have constitutive activation of NF- $\kappa \mathrm{B}$ [8]. Thus, SARS-CoV2 infection could induce further activation of the NF- $\mathrm{KB}$ pathway through the elevation of angiotensin II in elderly individuals and patients with diabetes, resulting in the development of severe COVID-19 pathology. The 
Fig. 1 Schematic presentation of angiotensin-II-NF- $\mathrm{KB}$ axis. ACE angiotensin-converting enzyme, AT1 receptor type 1 angiotensin receptor, $\mathrm{CBM}$ Carma3 (B-cell lymphoma 10), -Bcl 10 B-cell lymphoma 10, -MALT1 mucosa-associated lymphoid tissue lymphoma translocation protein 1 complex, NF-кB nuclear factor kappalight-chain-enhancer of activated

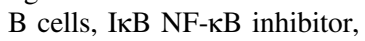
IKK IкB kinase, MCP-1 monocyte chemoattractant protein 1, PDGF-B plateletderived growth factor-beta

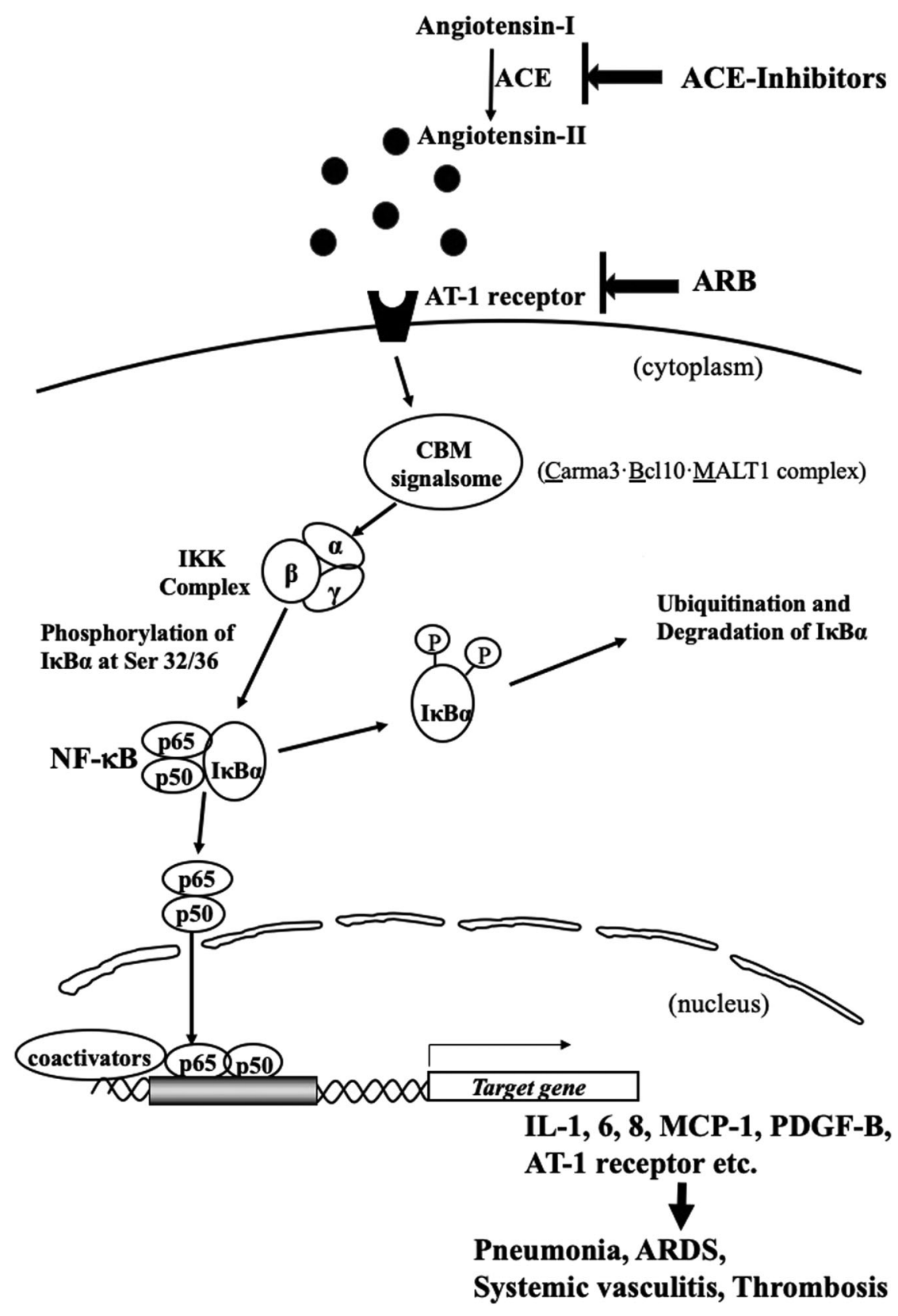

angiotensin-II-induced activation of NF- $\mathrm{KB}$ could be reversed by RAS inhibitors. Thus, the risk reduction among aged individuals and diabetes patients by RAS inhibitors might be explained by the angiotensinII-NF- $\mathrm{B}$ pathway interaction. Further clinical and biological studies in these patients are needed to draw a clearer picture regarding the risk reduction by RAS inhibitors.

\section{Compliance with ethical standards}

Conflict of interest The authors declare that they have no conflict of interest.
Publisher's note Springer Nature remains neutral with regard to jurisdictional claims in published maps and institutional affiliations.

\section{References}

1. Reynolds HR, Adhikari S, Pulgarin C, Troxel AB, Iturrate E, Johnson SB, et al. Renin-angiotensin-aldosterone system inhibitors and risk of Covid-19. N Engl J Med. 2020;382:2441-8.

2. Mancia G, Rea F, Ludergnani M, Apolone G, Corrao G. Renin-angiotensin-aldosterone system blockers and the risk of Covid-19. N Engl J Med. 2020;382:2431-40. https://doi.org/10. 1056/NEJMoa2006923.

3. Matsuzawa Y, Ogawa H, Kimura K, Konishi M, Kirigaya J, Fukui K, et al. Renin-angiotensin system inhibitors and the severity of 
coronavirus disease 2019 in Kanagawa, Japan: a retrospective cohort study. Hypertens Res. 2020. https://doi.org/10.1038/s41440-02000535-8.

4. de Abajo FJ, Rodríguez-Martín S, Lerma V, Mejía-Abril G, Aguilar M, García-Luque A, et al. Use of renin-angiotensinaldosterone system inhibitors and risk of COVID-19 requiring admission to hospital: a case-population study. Lancet 2020;395:1705-14.

5. Phillips MI, Kagiyama S. Angiotensin II as a pro-inflammatory mediator. Curr Opin Investig Drugs. 2002;3:569-77.
6. Iikuni N, Okamoto H, Kasahara M, Kamatani N. An angiotensin receptor blocker suppresses monocyte chemoattractant protein 1 production from rheumatoid synovial fibroblasts: comment on the article by Sagawa et al. Arthritis Rheum. 2005;52:4047-8.

7. Tornatore L, Thotakura AK, Bennett J, Moretti M, Franzoso G. The nuclear factor kappa B signaling pathway: integrating metabolism with inflammation. Trends Cell Biol. 2012;22:557-66.

8. Kriete A, Mayo KL. Atypical pathways of NF-kappaB activation and aging. Exp Gerontol. 2009;44:250-5. https://doi.org/10.1016/j. exger.2008.12.005. 